\title{
Study of Impact Strength, Hardness, Micro Structure and Tribological Properties of A15052 Composite with SiC and Graphite as Reinforcements
}

\author{
Shinoop Khan S, M A Joseph, K Sekar
}

\begin{abstract}
Aluminum Composite are widely used in aviation and automotive industries because it is light in weight hence it reduces the fuel consumption and improves the energy efficiency. The present work deals with preparing Aluminum-based particle reinforced composite fabricated through Stir Casting Process wherein Sic along with Graphite are used as reinforcements which has improved mechanical properties with reduction in weight. Impact toughness, hardness along with wear property of the fabricated composite samples were tested and compared with Al 5052 Cast Alloy based on ASTM Standard. From the testing, we can conclude that Impact toughness, Hardness and wear properties of Al 5052 base alloy is considerably increased due to the addition of particulate reinforcements. And also there is not much studies reported on the influence of Sic and Graphite as reinforcement on Impact toughness, hardness along with Wear behavior of Al 5052 alloy. So the objective of the current work is to fabricate Al 5052 base alloy reinforced with particulate composite by stir casting process and to study the Impact toughness, hardness, and microstructure along with wear behavior of the fabricated composites.
\end{abstract}

Keywords: Energy efficiency, Graphite, Hybrid Composite, Stir Casting

\section{INTRODUCTION}

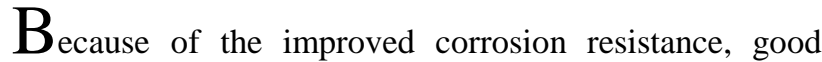
formability, increased strength and welding properties $\mathrm{Al}$ 5052 alloy has gained a lot of importance in Marine, automotive and aviation industries. Particle reinforced aluminum matrix composites have low density and also have increased impact toughness, hardness and improved wear behavior. Hence high specific strength, hardness and wear resistance result to make ideal material for light weight structural, automobile and aerospace applications.

The present work includes the fabrication of Al 5052 alloy-based composite component using Reinforcement such as Silicon Carbide with a fixed weight fraction of $1 \%$ and Graphite powder having weight fraction $0.5 \%, 1 \% \& 1.5 \%$ respectively. To improve Impact strength, hardness, specific

Revised Manuscript Received on July 05, 2020.

* Correspondence Author

Shinoop Khan $\mathbf{S} *$, $\mathbf{M}$ tech Material Science and Technology, Department of Mechanical Engineering, NIT Calicut, Kerala, India. E-mail: khanshinoop@gmail.com

Dr M A Joseph, Professor Department of Mechanical Engineering, NIT Calicut, Kerala, India. E-mail: joseph@nitc.ac.in

Dr K Sekar ,Assistant Professor Department of Mechanical Engineering,NITCalicut,Kerala, India. E-mail :sekar@nitc.ac.in
Strength, stiffness along with wear resistance reinforcement particles are added to Al 5052 base alloy by Stir casting process. Most economical method for fabricating aluminum matrix composite is Stir casting Methodology Hardness values of the composite and cast alloy is measured by Vickers hardness test. Standard metallurgical preparation and Imaging technique is used for the characterization of microstructure .Imaging techniques such as Optical microscopy and Scanning Electron Microcopy (SEM) is used for examining the microstructure. Toughness of the specimen is obtained by conducting Charpy test. Impact strength is the measure of toughness, it is the amount of energy absorbed before fracture. Wear behavior of $\mathrm{Al} 5052$ is can be analyzed by conducting pin on disc wear apparatus by varying sliding velocity with normal load and keeping sliding distance as constant

\section{EXPERIMENTAL PROCEDURE}

\section{A. Matrix Metal}

Matrix used in this fabrication process is Al 5052 base alloy of aluminum. Al 5052 alloy having main alloying element as magnesium along with small amount of manganese and chromium. The components present in $\mathrm{Al} 5052$ is given in Table I.

Table I: Component present in Al 5052 base Alloy

\begin{tabular}{|c|c|c|c|c|c|c|c|c|}
\hline $\begin{array}{c}\text { Ele } \\
\text { ment }\end{array}$ & $\mathrm{Fe}$ & $\mathrm{Si}$ & $\mathrm{Mg}$ & $\mathrm{Mn}$ & $\mathrm{Cu}$ & $\mathrm{Zn}$ & $\mathrm{Cr}$ & $\mathrm{Al}$ \\
\hline $\begin{array}{c}\% \\
\begin{array}{c}\text { Perc } \\
\text { ent }\end{array}\end{array}$ & 0.2 & 0. & 2.5 & 0.0 & 0.0 & 0.0 & 0. & $\mathrm{Re}$ \\
21 & & 6 & 2 & 1 & 16 & $\begin{array}{c}\text { mai } \\
\mathrm{n}\end{array}$ \\
\hline
\end{tabular}

\section{B. Reinforcement Material}

The reinforcement materials used is Silicon carbide of particle size 50 micron and Graphite powder of size 60 micron. To prepare Al 5052/SiC/Gr hybrid composite aluminum alloy 5052 is added with Silicon carbide and Graphite as reinforcing member.

\section{Stir Casting Technique}

The Stir casting methodology is the easiest and economical method used for the fabrication of $\mathrm{Al} 5052$ base alloy composites. The figure Fig.2.1 shows the schematic explanation of Stir casting process.

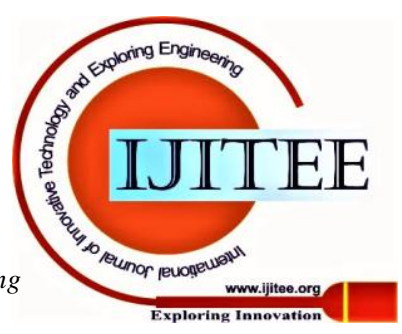


The procedure followed in stir casting process for the fabrication of Al 5052 base alloy composite with Sic and Gr as reinforcement is listed below

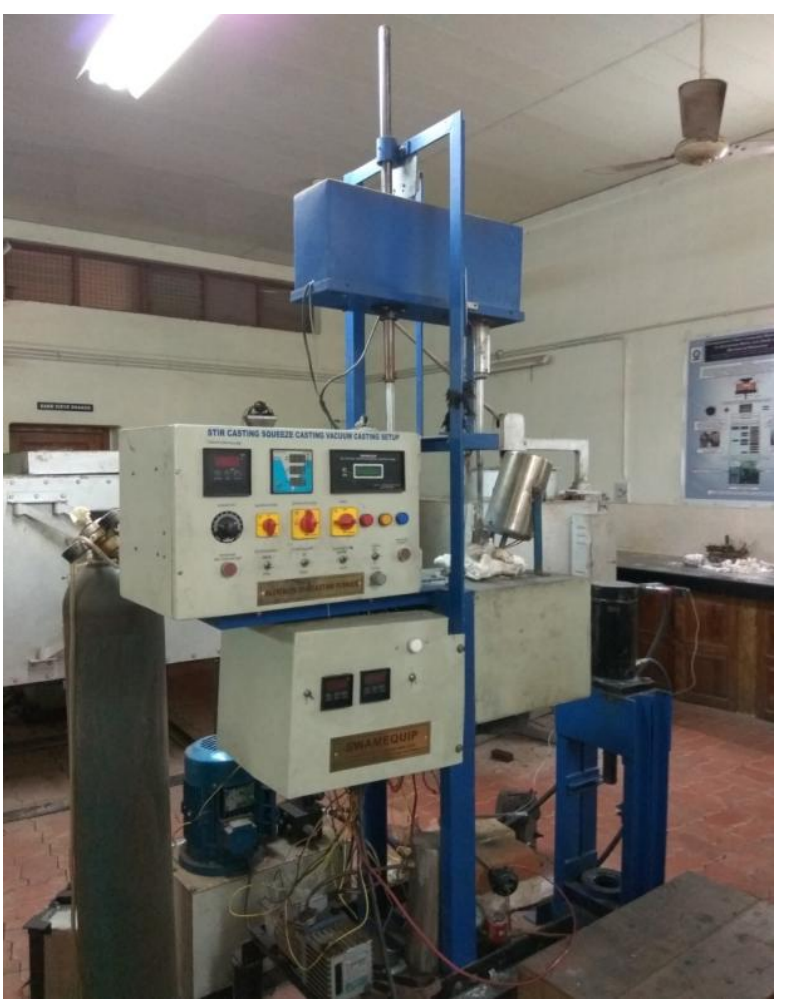

Fig.2.1. Stir Casting Process

- Material is cut and weighed to $1.2 \mathrm{~kg}$ and kept inside the furnace

- Melting the material keeping furnace temperature of $850^{\circ} \mathrm{C}$.

- Slag removing agent such as Bi-potassium hexa fluro titanate (K2TiF6) is added to the furnace

- Preheat Reinforcement particle up to $650^{\circ} \mathrm{C}$ for 30 minutes

- Preheated reinforcement Slow added to molten metal in order to prevent casting from agglomeration.

- $\quad$ Stirrer is operated at $450 \mathrm{rpm}$ and stirring is done for 15 minutes

- Open the bottom valve of the furnace and pour the molten metal in to die cavity and allowed to solidify

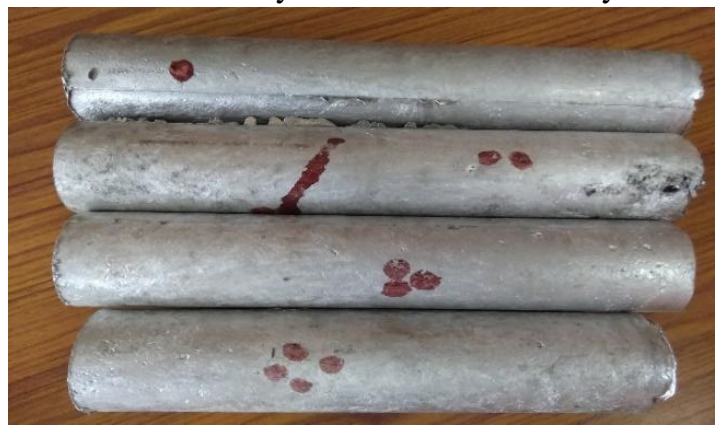

Fig 2.2 Cast alloy and Composites

\section{Charpy Test}

Charpy test is conducted on Al 5052 Cast alloy and fabricated particulate reinforced composite samples according to ASTM E23 standard. The impact strength values of Al 5052 cast alloy and $\mathrm{Al}$ 5052/Sic/Gr shown in Fig.2.4. Al 5052 cast alloy is showing less toughness compared to Composite. From Fig.2.3 By keeping weight fraction of Sic to 1 percentage and adding 0.5 percentage Graphite toughness of Al 5052 composites are increased $41 \%$ compared to base alloy this is due to optimum feed rate and homogeneous distribution of reinforcement. By increasing the concentration of reinforcements, material can absorb more energy compare to cast alloy up to Weight fraction of $1 \%$.

\section{Impact Strength (J)}

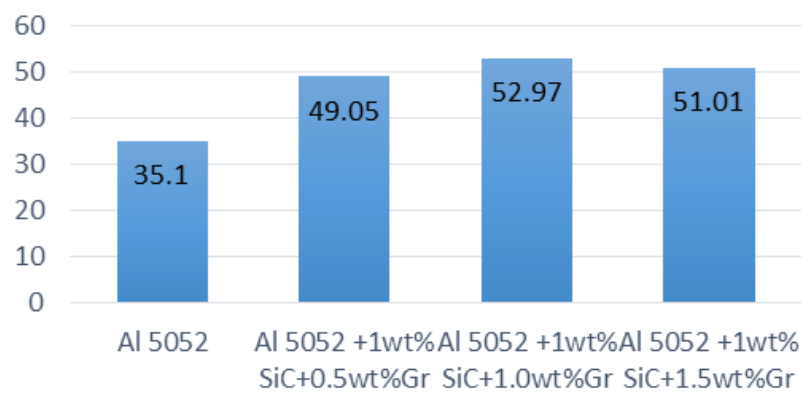

Fig.2.3 Impact strength of cast alloy and composite

\section{E. Hardness Test}

Vickers Hardness test performed on Al 5052 Cast alloy and hybrid composite samples according to ASTM E92 standard. It uses a diamond pin indenter with inclined angle of $136^{\circ}$ with a load of $5 \mathrm{Kgf}$. The Vickers Hardness values of Al 5052 cast alloy and $\mathrm{Al}$ 5052/SiC/Gr shown in Fig.2.4. By keeping weight fraction of Sic to 1 percentage and adding 0.5 percentage Graphite hardness of Al 5052 composites are increased $21 \%$. As Graphite concentration increases from 1 to $1.5 \%$ hardness value decreases.

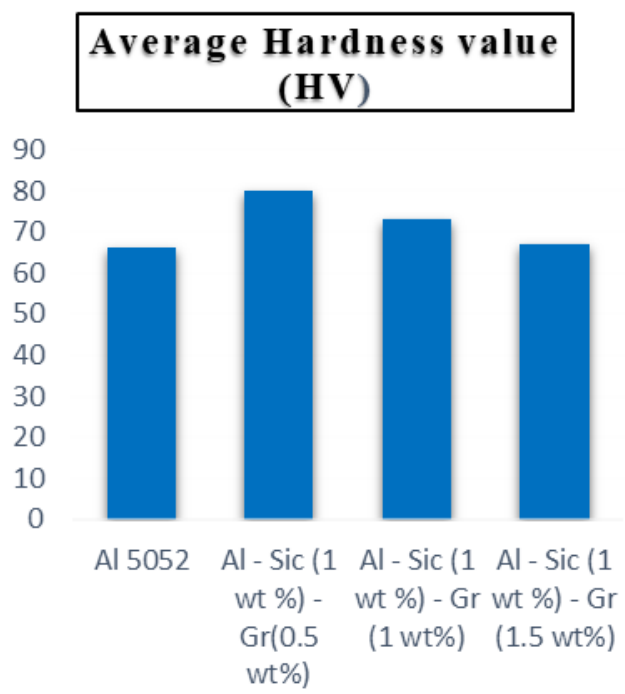

Fig.2.4 Hardness Value of Cast Alloy and Composite

\section{F. SEM Micro Structure}

The microstructure of $\mathrm{Al} 5052$ Cast alloy and Composite is examined using Scanning Electron Microscopy to identify surface texture as shown in Fig. 2.5 (a-d)

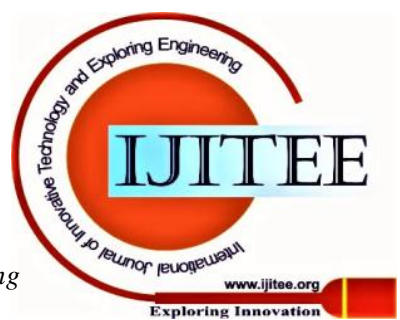



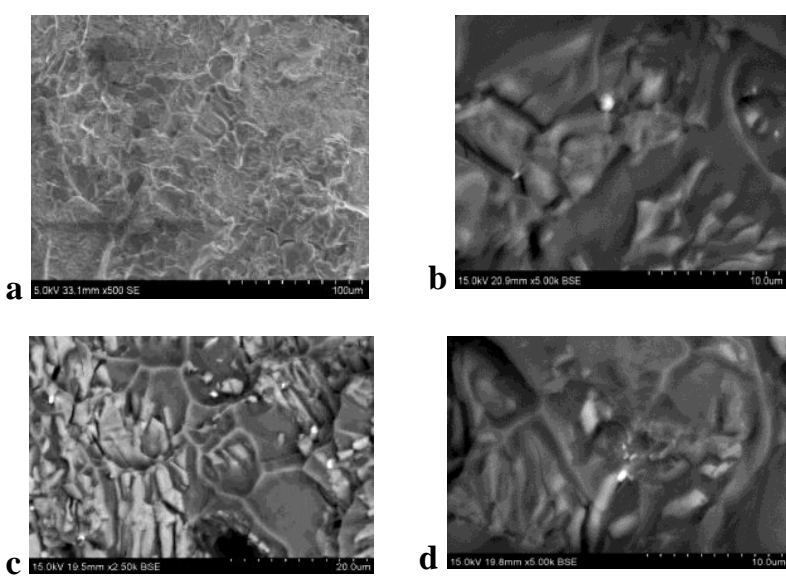

Fig.2.5 SEM Images a) Al 5052 Cast alloy b)Al 5052 - SiC (1 wt \%) - Gr (0.5 wt\%) c) Al 5052 - SiC (1 wt \%) - Gr (1 wt\%) d)Al 5052 - SiC (1 wt \%) - Gr (1.5 wt\%)

SEM morphology described good surface texture of $\mathrm{Al}$ 5052/SiC/Gr hybrid composite. Pure Al 5052 cast alloy there is no reinforcement particle. From (b-c) $\mathrm{SiC}$ hard ceramic particles are dispersed uniformly with varying weight percent 0.5 to $1 \mathrm{wt} \%$, due to proper stirrer rpm.

\section{G. Wear Test}

To conduct wear analysis, wear test samples prepared according to ASTM G99.Using pin on disc wear apparatus wear test is conducted. Using abrasive grade of 400,600 and 1000 end surface of the specimen is polished and cleaned. The test specimen and disc are properly cleaned with acetone before and after the test. Wear is calculated based on the weight loss, by measuring weight of the specimen before and after the test. In this wear analysis Parameters for the wear test is load applied $(20 \mathrm{~N}, 30 \mathrm{~N}, 40 \mathrm{~N})$ and sliding velocity $(2 \mathrm{~m} / \mathrm{s}, 3 \mathrm{~m} / \mathrm{s}, 4 \mathrm{~m} / \mathrm{s})$ by keeping sliding Distance as a constant value of $1200 \mathrm{~m}$

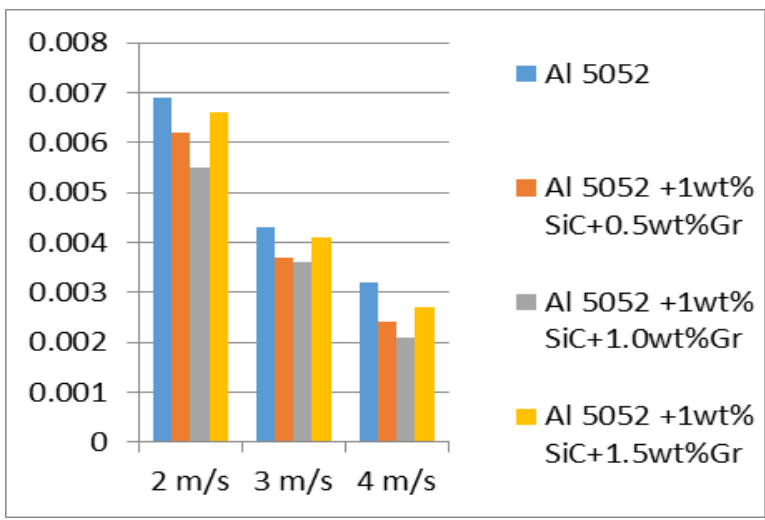

Fig 2.6 Weight loss $(\mathrm{g})$ for $\mathrm{Load}=20 \mathrm{~N}$

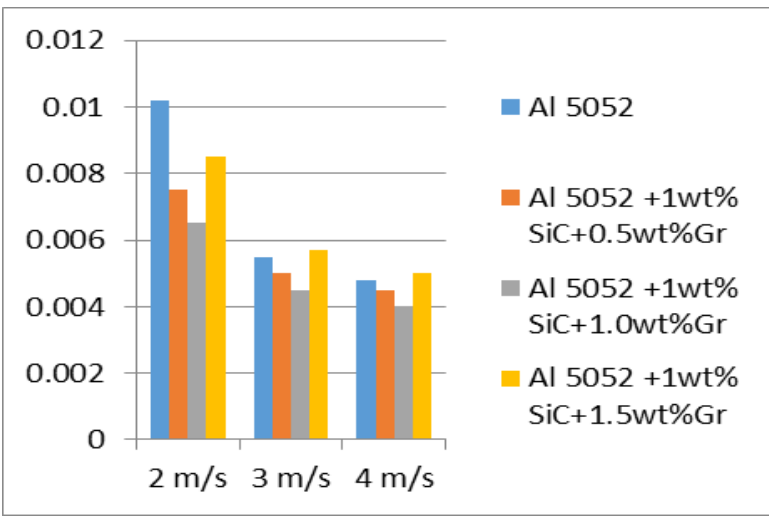

Fig 2.7 Weight $(g)$ for $\operatorname{Load}=30 \mathrm{~N}$

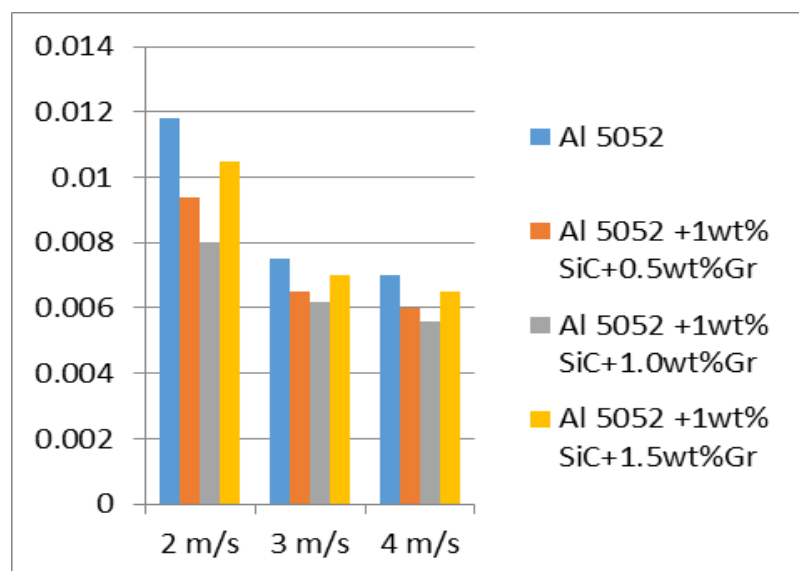

Fig 2.8 Weight loss $(\mathrm{g})$ for $\mathrm{Load}=40 \mathrm{~N}$

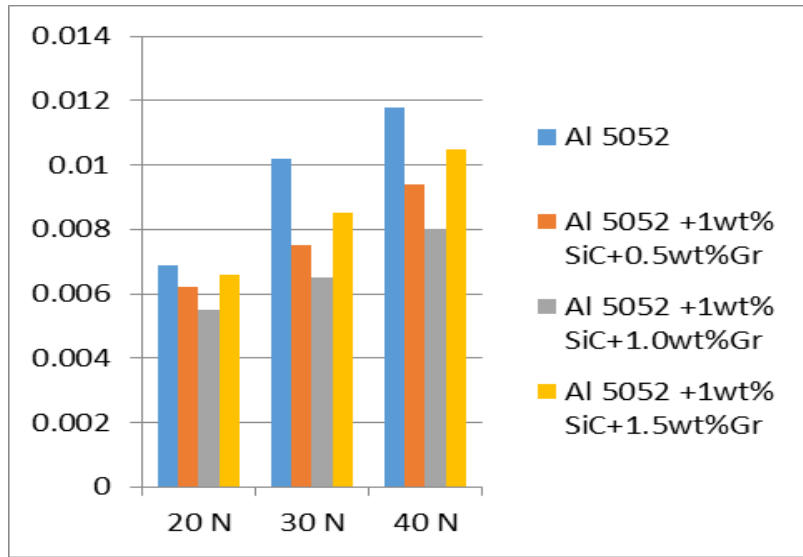

Fig 2.8 Weight loss (g) for velocity $=2 \mathrm{~m} / \mathrm{s}$

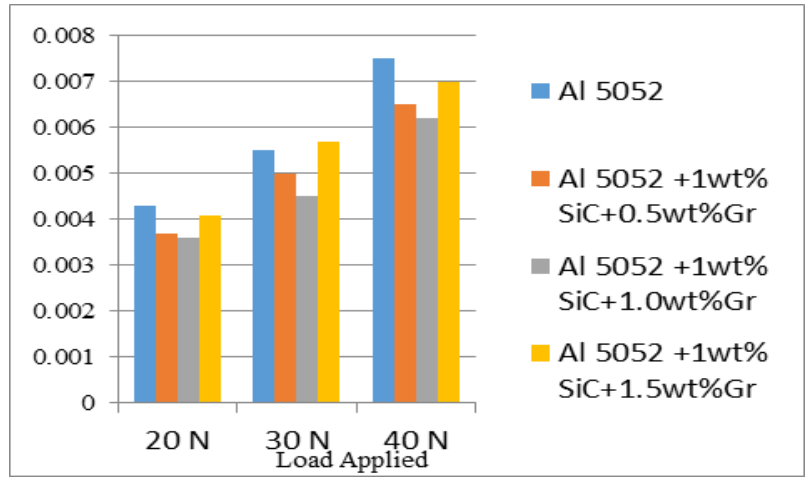

Fig 2.9 Weight loss $(\mathrm{g})$ for velocity $=3 \mathrm{~m} / \mathrm{s}$

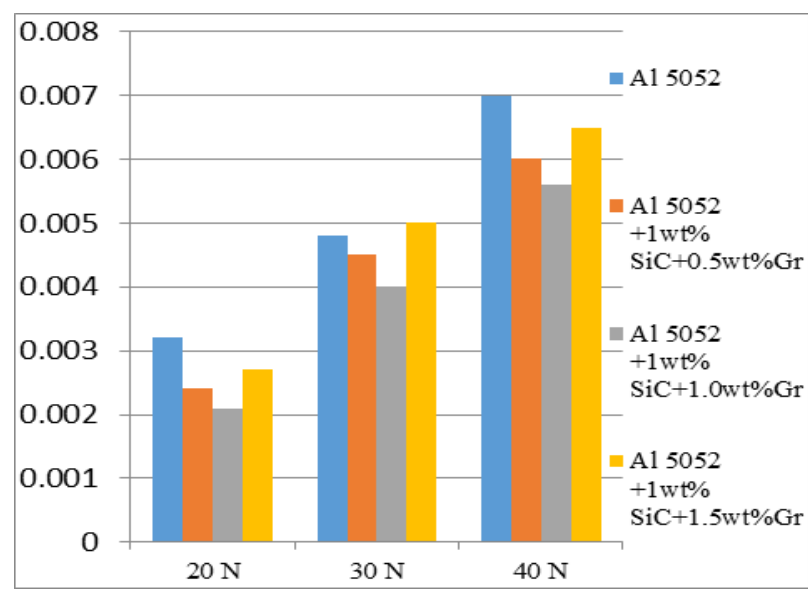

Fig 2.10 Weight loss $(\mathrm{g})$ for velocity $=4 \mathrm{~m} / \mathrm{s}$

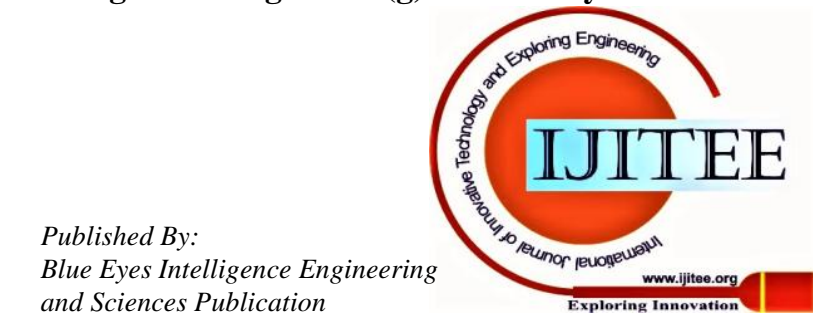




\section{RESULT AND DISCUSSIONS}

1. Using Stir Casting process Al-Sic-Gr of various concentration composites were made and different testing listed above is also conducted

2. By keeping weight fraction of Sic to 1 percentage and adding 0.5 percentage Graphite hardness of $\mathrm{Al} 5052$ composites are increased $21 \%$.

3. As Graphite concentration increases from 1 to $1.5 \%$ hardness value decreases.

4. Al 5052 cast alloy is showing less toughness compared to Composite. By keeping weight fraction of $\mathrm{Sic}$ to 1 percentage and adding 0.5 percentage Graphite toughness of Al 5052 composites are increased $41 \%$ compared to base alloy this is due to homogeneous distribution and optimum feed rate of reinforcement.

5. By increasing the concentration of reinforcements, material can absorb more energy compare to cast alloy, Up to a weight fraction of $1 \%$

6. As we increases the sliding speed wear rate decreases and also we increases the normal load on contact surfaces wear increases

\section{CONCLUSION}

From this study we can infer that properties of Al 5052 can be improved by addition of Sic and Graphite reinforcement. Microstructure analysis through SEM indicate that particles in the composites are uniformly distributed. By increasing weight fraction reinforcement up to $1 \%$ Hardness Value and impact toughness of the composite is increases. When the Weight fraction Gr increases wear loss decreases up to an optimum weight fraction of $1 \%$. these because of the lubricating effect of graphite reinforcement. As the sliding speed increases wear decreases. This is because of temperature raise at the contact surface due to increase in sliding speed. So the contact surface get oxidized due to this temperature raise. Low wear rate of the composite occurs due to hard nature of formed oxide layer. Material removal rate is low at higher sliding speed due to less time of contact between interacting surfaces. As the load on the contact surface increases wear increases this is due to the higher contact pressure at the sliding surface

\section{REFERENCES}

1. K. Sekar, K. Allesu, M. A. Joseph, -Mechanical and wear properties of al-A12O3 metal matrix composites fabricated by the combined effect of stir and squeeze casting method\|, Trans Indian Inst,vol 68(2), 2015. pp115-121.

2. Muhammad Hayat Jokhio, Muhammad Ibrahim Panhwar, and MukhtiarAli Unar, -Manufacturing of aluminum composite material using stir casting processl, Mehran university research journal of engineering \& technology, volume 30, no. 1,pp 53-64.

3. S. BalasivanandhaPrabu, L. Karunamoorthy, S. Kathiresan, B. Mohan, - Influence of stirring speed and stirring time on distribution of particles in cast metal matrix compositell, Journal of Materials Processing Technology 171 (2006) 268-273

4. Khalid Almadhoni, Sabah Khan, - Review of effective parameters of stir casting process on metallurgical properties of ceramics particulate al composites\|, IOSR Journal of Mechanical and Civil Engineering, Volume 12, Issue 6, Ver. IV , PP 22-40

5. H. Abdizadeh and M. A. Baghchesara, -Investigation into the mechanical properties and fracture behavior of A356 aluminum alloy-based zro2-particle-reinforced metal-matrix composites\|,Mechanics of Composite Materials, Vol. 49,pp. 849-858
6. J.K.Sahoo, S.K.Sahoo, H.Sutar and B.Sarangi, -Wear behavior of Al-Si alloy based metal matrix composite reinforced with TiB2\|, National Conference on Processing and Characterization of Materials, IOP Conf. Series: Materials Science and Engineering 178,pp 1-10

7. Jamaluddin Hindi, AchutaKini U, S.S Sharma, -mechanical characterization of stir cast aluminium 7075 matrix reinforced with grey cast iron \& fly ash\|, International Journal of Mechanical and Production Engineering, Volume- 4,127-132

8. Mohsen Hossein-Zadeh, OrnidMirzaee, PeymanSaidi, - Structural and mechanical characterization of Al-based composite reinforced with heat treated A103 particlell, Materials \& Design, Volume 54, February 2014, pp. 245-250.

9. V. L. Kingston, M. John Prabhakar, N. Senthil Kumar, -Study on mechanical characteristics of hybrid metal matrix composite

\section{AUTHORS PROFILE}

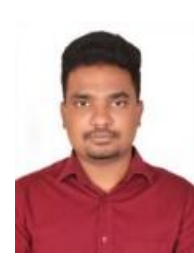

Shinoop khan Student E-mail:khanshinoop@gmail.com Educational Qualifications M. Tech., Materials Science and Technology (Mechanical), NIT Calicut,2018-2020 B.Tech., Mechanical, University of Kerala, 2010-2014

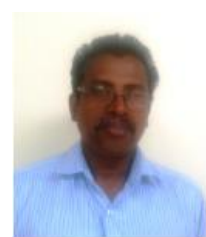

Dr.M A Joseph , Professor E-mail: joseph@nitc.ac.in Educational Qualifications Ph. D., Material Science, University of Calicut, 2002 M. Tech., Production (Mechanical), IIT Madras, 1988 B. Sc. (Engg.), Mechanical, University of Kerala, 1982 Honours And Awards

1.Best paper award, Powder Metallurgy Association of India, National Conference on P/M (NCPM-2000) held in IIT Chennai in Feb 2000

MEMBERSHIP OF SCIENTIFIC AND PROFESSIONAL SOCIETIES

1.Life Member, ISTE

2.Member, Institute of Indian Foundry men

3.Member, System Society of India

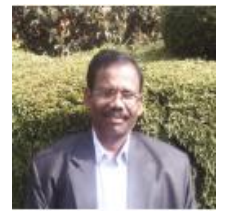

Dr.K Sekar , Assistant Professor E-mail: sekar@nitc.ac.in Educational Qualifications Ph.D Manufacturing Engineering, (National Institute of Technology Calicut, Government of India, Kerala) (2015) M.E - Manufacturing Engineering, (Government College of Technology Coimbatore, Tamilnadu) (2002) B.Tech - Production Engineering, (Government College, Madras Institute of Technology, Chennai, Tamilnadu) (1998) B.Sc - Physics (Government College,University of Madras, Chennai, Tamilnadu) (1994)

Best paper award

International Award from World Research Council - Innovation Research in Design and development of multiple casting machine for composite materials, 2018.

Best Paper award and Presentation at International Conference on "Futuristic Trends In Materials and Manufacturing" at Delhi Technical Campus during 26-27 October, 2018

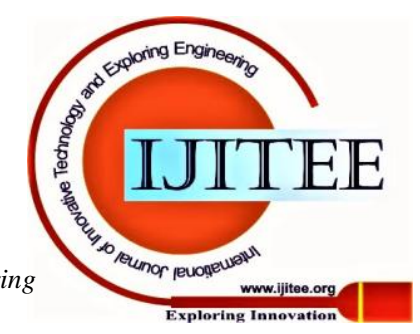

